\title{
SOBRE COOPERAÇÃO E COOPERATIVAS EM ASSENTAMENTOS RURAIS
}

\author{
Rosemeire Aparecida Scopinho \\ Universidade Federal de São Carlos, São Carlos, Brasil
}

RESUMO: O artigo trata do significado da cooperação e do cooperativismo no processo organizativo de assentamentos rurais no estado de São Paulo. Compreendendo cooperação e cooperativismo como processos sociais distintos, discuto os motivos do movimento de institucionalização de cooperativas na sua relação com o declínio das formas de cooperação tradicionalmente desenvolvidas no mundo rural brasileiro. Analiso o significado da cooperação e os problemas decorrentes da sua institucionalização no interior dos assentamentos rurais organizados pelo Movimento dos Trabalhadores Rurais Sem Terra (MST), procurando identificar os elementos que indicam mudanças e permanências em relação ao tradicional cooperativismo rural. Procuro refletir sobre os motivos da atual tendência existente entre os assentados para refutar a cooperativa como modelo organizacional, mas valorizar a cooperação como modo de organização da vida econômica e societária.

PALAVRAS-CHAVE: Cooperação; cooperativismo; assentamentos rurais.

\section{ABOUT COOPERATION AND COOPERATIVISM IN RURAL SETTLEMENTS}

ABSTRACT: This article deals with the meaning of cooperation and cooperativism in the organizational process of rural settlements in the state of São Paulo considering cooperation and cooperativism as distinct social processes. I discuss the motive why the movement headed for cooperative institutionalization in relation to the decline of the traditional ways of cooperation developed in the Brazilian rural world. The meaning of cooperation was studied as well as subsequent problems due to its institutionalization within the rural settlements organized by MST - Landless Workers Movement, trying to identify the elements that show change and permanence related to traditional rural cooperativism. I seek to reflect upon the motives of the current trend among settlers to reject the cooperative as an organizational model, despite the fact they appraise cooperation as a way to organize their social and economic life.

KEYWORDS: cooperation, cooperativism, rural settlement.

Diante da busca de alternativas para a crise de emprego, a problemática da organização e gestão de assentamentos rurais com base no associativismo tem sido objeto de investimento das políticas públicas e, sobretudo, campo de disputa de projetos de desenvolvimento econômico-social (Leite, Heredia, Medeiros, Palmeira \& Cintrao, 2004; Ministério do Desenvolvimento Agrário, 2000).

Ao estudar as relações de trabalho e as contradições do processo organizativo em um assentamento organizado pelo Movimento dos Trabalhadores Rurais Sem Terra (MST), localizado na região de Ribeirão Preto-SP, depareime com um complexo e contraditório universo de sentidos atribuídos pelos assentados à cooperação e às cooperativas (Scopinho et al, 2005). No âmbito das relações de trabalho, a cooperação significa, por um lado, a ampliação da capacidade de sobrevivência econômica através da obtenção de renda monetária, direta e/ou indireta, maior (gerada, principalmente, pelo aumento da produtividade do trabalho e da redução dos custos de produção); o aprendizado de formas solidárias e agroecológicas de trabalhar a terra; a possibilidade de melhorar a infra-estrutura produtiva, entre outras vantagens. Por outro lado, o trabalho cooperado explicita ainda mais a diversidade sócio-cultural e a heterogeneidade dos projetos de trabalho e de vida existentes, as divergências e a predominância dos valores individualistas e, na prática, não elimina as desigualdades e as relações de subordinação típicas do trabalho heterogerido. Contudo, fora do trabalho, no cotidiano das famílias, a cooperação espontânea dá continuidade ao movimento político de luta pela melhoria das condições de vida, amplia e dinamiza as formas e as redes de convivência social que favorecem a resistência e a permanência no assentamento, chegando mesmo a configurar um padrão de assistência social próprio, uma vez que a escassez generalizada torna precárias as condições de vida nesses espaços.

A cooperação manifesta-se com mais clareza externamente às relações de trabalho, embora no mundo rural o trabalho e as outras dimensões da vida cotidiana nem sempre estejam nitidamente delimitadas. Evidencia-se, cada vez mais, uma tendência existente entre os assentados para refutar a cooperativa como modelo organizacional, mas valorizar a cooperação como modo de organização da vida econômica e societária. Ocorre a fuga da institucionalização, sob a alegação de que isto burocratiza e retira a autonomia, e a retomada das tradicionais formas de organização do trabalho baseadas na cooperação espontânea, 
porque, de fato, cooperar é imprescindível para a sobrevivência desses trabalhadores. Porém, como o associativismo formal tem sido colocado pelo Estado como uma das condições para legalizar os assentamentos, geralmente, opta-se por organizar o que Schneider (1981, p. 31) chamou de "cooperativismo típico", porque a cooperação entre os produtores não se dá no plano do processo de trabalho, mas da prestação de serviços necessários para produzir (assistência técnica, repasse de crédito, beneficiamento, comercialização), por delegação de responsabilidade dos associados à diretoria administrativa.

Neste artigo proponho-me a refletir sobre o significado que tem assumido, historicamente, a cooperação e o cooperativismo nas relações de trabalho rural no Brasil. A reflexão é feita com base em revisão da literatura e análise de documentos produzidos pelo Setor de Produção, Cooperação e Meio Ambiente do MST. Outra importante fonte de informações, que tanto instigou como alimentou esta reflexão, é a minha própria experiência neste campo de pesquisa, que se acumula desde 1996 e se realiza através de observações do dia-a-dia nos assentamentos, de entrevistas com integrantes do MST e assentados e da participação em seminários, debates, reuniões, processos de formação, entre outras atividades realizadas pelo movimento, que constituem momentos privilegiados para conhecer esta realidade.

As experiências de cooperação/cooperativismo desenvolvidas pelo MST têm sido referidas na literatura especializada tanto pelas polêmicas que suscitam quanto pelo pioneirismo na introdução do debate, na formulação de diretrizes e na implementação de práticas no âmbito da economia popular. Essa reflexão pode servir como um recurso analítico importante e necessário para o entendimento das contradições, dos limites e das potencialidades presentes nas relações de trabalho cooperado e autogestionário que se procura desenvolver nos assentamentos oriundos da reforma agrária recente.

Primeiramente, discuto os motivos do movimento de institucionalização de cooperativas na sua relação com o declínio das formas de cooperação tradicionalmente desenvolvidas no mundo rural brasileiro, para depois analisar o significado da cooperação e os problemas decorrentes da sua institucionalização no interior dos assentamentos rurais organizados pelo MST, procurando identificar os elementos que indicam mudanças e permanências em relação ao tradicional cooperativismo rural brasileiro.

\section{Cooperação e cooperativismo no Brasil rural}

Cooperação e cooperativismo são processos sociais distintos e não é de hoje que a literatura mostra que pode não haver correspondência direta entre eles (Araújo, 1982; Camargo, 1960; Fleury, 1983; Maia, 1985; Rios, 1976; Singer, 2002). Cooperativa é entendida aqui como modelo de estrutura organizacional, do qual se originam socie- dades constituídas sob a forma democrática para atingir fins específicos, ou seja, associação autogestionária de pessoas, regida por princípios igualdade no que se refere à propriedade, gestão e repartição de recursos (Camargo, 1960; Fleury, 1983; Rios, 1976). Cooperativismo é um movimento social ou doutrina, cuja corrente hegemônica é a rochdaleana, que se caracteriza pela preocupação política de transformação social aceitando a idéia de que a infra-estrutura pode determinar mudanças na superestrutura social (Camargo, 1960; Pinho, 2004). Cooperação é ação social articulada, alinhavada por objetivos comuns para solucionar problemas concretos que, por sua vez, é aqui entendida em dois sentidos: (a) como ação-padrão, racionalmente construída à luz de um código e desenvolvida no interior de cooperativas por sujeitos inseridos numa certa divisão social do trabalho, os quais têm objetivos comuns e compartilham benefícios ou prejuízos de forma eqüitativa (por exemplo, o que se pratica de acordo com o regimento interno); (b) como ação espontânea inerente a determinados grupos e derivada de suas tradições e costumes, pré-existente às instituições, fundamentada na reciprocidade adiada - a retribuição é feita quando for possível ou conveniente - ou instantânea - a retribuição é imediata (Bruni, 2005; Camargo, 1960).

Camargo (1960), estudou a relação estabelecida entre cooperação e cooperativismo na zona rural do estado de São Paulo na primeira metade do século XX constatando que, embora existissem formas espontâneas de cooperação, especialmente o mutirão, a troca de dias e auxílios mútuos, ${ }^{1}$ não havia correlação positiva entre elas e o cooperativismo. Não havia um sistema cooperativista, pois os diferentes tipos de cooperativas não se articulavam. Nas cidades rurais ou tipicamente rurais, predominava o cooperativismo de produção, mas as cooperativas não passavam de casas comerciais atacadistas que antecediam o comércio e desapareciam com o seu desenvolvimento. A cooperação espontânea era um valor presente nos grupos rurais como forma de lidar com a escassez, de solucionar problemas e necessidades concretas, mas não tinha nenhuma relação com as cooperativas que seguiam uma lógica estritamente economicista. As propriedades rurais, em grau crescente de mecanização, voltavam-se para as monoculturas especializadas e o desenvolvimento do cooperativismo encontrava obstáculos, porque ocupava uma posição subordinada e dependente no sistema produtivo dominante, procurando a ele se acomodar.

No Brasil, não é de hoje que o cooperativismo rural tem sido visto como mecanismo de modernização da agricultura, estratégia de crescimento econômico ou instrumento de mudança social. Muitos autores remeteram-se à dupla face - popular e institucional - deste movimento, colocando em questão o seu caráter de contestação ou de controle social. 
Para Schneider (1981), o cooperativismo rural brasileiro tem procurado harmonizar as dimensões econômicas, sociais e culturais do processo de desenvolvimento do país, independentemente das condições estruturais concretas às quais ele se sobrepõe. Para Rios (1976), embora a fórmula organizacional cooperativa tenha se generalizado no Brasil e no mundo, cada experiência torna-se específica e condicionada pelo tempo histórico em que se desenvolve, pelo regime econômico-político, pelo estágio tecnológico da sociedade, pela capacidade organizativa e política e pela ação concreta dos sujeitos. Por este motivo, Novaes (1981) e Schneider (1981) alertaram para o fato de que, ao analisar cooperativas, é necessário considerar o contexto sócio-histórico em que elas aparecem, porque conhecer o significado e as repercussões das diferentes experiências exige a análise das condições estruturais concretas da sociedade. Schneider (1981) mostrando que, apesar dos incentivos estatais, o cooperativismo rural brasileiro desenvolveu-se de modo seletivo em determinadas regiões e setores agropecuários, concluiu:

O cooperativismo típico, quando sobreposto a uma base produtiva desigual comandada pela 'livre iniciativa', tende a aprofundar as desigualdades existentes. Na verdade, o sistema opera dentro de um marco de mudanças 'permitidas' que, do ponto de vista estrutural, são necessariamente marginais. Por isso, continua utópico pensar-se que este cooperativismo individualista, inserido no contexto de uma formação social que tem no capitalismo o seu modo de produção dominante, atue no sentido de reverter a dinâmica da expansão do capital e das forças sociais que sustentam este processo (1981, p. 31).

Para Rios (1989, p. 47), o surgimento deste movimento no Brasil ${ }^{2}$ foi uma caricatura “... mera transposição mecânica de normas adotadas por uma única cooperativa de consumo inglesa ${ }^{3}$." [itálicos do autor] e ocorreu "... sob uma dupla e contraditória face" (p. 9), pois tanto foi um instrumento de organização econômica da agricultura de exportação desenvolvida por latifundiários capitalizados quanto foi utilizado para a promoção sócio-econômica dos pequenos produtores rurais e artesãos ao tentar solucionar os seus problemas de comercialização. Por isto, para este autor, o cooperativismo é uma ideologia niveladora de classes sociais distintas, que se contradiz porque longe de superar a diferenciação de classes a reproduz no seu interior: "A cada classe sua cooperativa." (p. 10). É exatamente esta dupla diferenciação que faz do cooperativismo tanto uma ideologia conservadora quanto transformadora das relações sociais, pois tendo o seu surgimento e o seu desenvolvimento historicamente situados as cooperativas tanto podem ser condicionadas pelos interesses das classes dominantes quanto podem favorecer os interesses das classes dominadas.
Estudos datados das décadas de setenta e oitentatempo que coincide com a chamada "modernização" agrícola brasileira realizada sob a Revolução Verde e com reformulação da legislação cooperativista que resultou na aprovação da lei 5.764 de 16/12/71 ${ }^{4}$ em vigor até hoje demonstraram que as cooperativas rurais privilegiam grandes proprietários em detrimento dos pequenos (Fleury, 1983; Novaes, 1981; Schneider, 1981), o seu caráter reprodutor das relações sociais capitalistas (Cavendish, 1981; Loureiro, 1981), que elas são instrumento de controle político e social (Rios, 1976). Esses estudos mostraram como o cooperativismo pode ser usado para favorecer grandes produtores agro-exportadores, minimizando o processo de descapitalização e auxiliando na sobrevivência deles sem, no entanto, alterar a desigualdade social.

Rios (1989) apontou que este tipo de cooperativismo, doutrinário $^{5}$, tem dupla finalidade: econômica - porque é rentável para os empresários - e política - porque é saída honrosa para os que não possuem capacidade competitiva individual. É apresentado como "tábua de salvação econômica" para os pobres, mas, equivocadamente, reflete a ideologia liberal clássica, porque pressupõe uma economia de pequenas e médias empresas que funcionam em regime de concorrência perfeita, o que nunca foi realidade no mundo e muito menos no Brasil, país cuja economia é dependente e condicionada pelo capital internacional. Esta ideologia, revestida de apelo igualitário e humanista, é funcional para remendar os graves problemas econômicos e sociais num momento histórico marcado pela presença de grandes corporações, pois trabalha com a idéia de que basta os pequenos se unirem para terem força.

Se fracassarem, tudo se resume em um problema de relacionamento entre indivíduos. Fracassaram não por uma situação de classe desvantajosa, pela falta de acesso aos centros de decisão política e de controle dos instrumentos econômico-financeiro reguladores do mercado e de preços de seus produtos, mas apenas porque, como indivíduos 'ignorantes e ineficientes', são incapazes de 'cooperar' (Rios, 1989, p. 58).

Oque este autor chamou de cooperativa transformadora resulta, geralmente, da ação político-econômica informal de movimentos populares, experiências autônomas desenvolvidas no nordeste brasileiro, em comunidades rurais e indígenas, que se caracterizam pela propriedade, gestão e distribuição cooperativa, constituindo meios para superar dificuldades econômicas e políticas ao manter a unidade entre o uso e o controle da organização. E como, na prática, os princípios podem não se traduzir em realidade, constituindo "letra morta" nos estatutos e regimentos internos, coloca-se a importância de verificar, em cada caso, como e porque se dá o fenômeno do distanciamento entre 
princípios e práticas, tendo como critério de identificação não o enquadramento jurídico, a mera adesão de um grupo de pessoas a princípios abstratos da doutrina cooperativista e estruturas jurídicas e burocráticas formais, mas o funcionamento real, em relação à propriedade, gestão e distribuição de recursos financeiros.

Em suma, o debate a respeito do significado do cooperativismo rural brasileiro não é novo e as suas contradições vêm sendo apontadas nãoé de hoje. Destaca-se aquela que reside no fato de a organização cooperativa beneficiarse das condições estruturais para crescer privilegiando o econômico em detrimento do social, ao mesmo tempo em que se mostra incapaz de enfrentar os condicionantes estruturais que dificultam o desenvolvimento dos seus princípios democráticos. As perspectivas atualmente apontadas para superar tal contradição também não são novas e passam por: ampliar a reflexão sobre a natureza, o significado e o destino do movimento cooperativista, o que pode contribuir com a formação de uma consciência política participativa; reorientar estímulos de créditos que favoreçam a organização dos pequenos; realizar uma reforma agrária planejada que democratize a estrutura fundiária e incentive a posse coletiva e não a propriedade de terras, entre outras.

A partir da década de 1980, no bojo das grandes transformações em curso no mundo do trabalho rural, o cooperativismo passou a ter outras configurações jurídicas e outros significados no universo das relações de trabalho. De um lado, surgiram as cooperativas de mão-de-obra, tidas como fraudulentas e mais conhecidas como "coopergatas"; de outro lado, as cooperativas e associações de pequenos produtores assentados, tidas como estratégia de luta social em favor da reforma agrária e da melhoria das condições de vida dos trabalhadores rurais.

Na agricultura paulista, as cooperativas de mão-de-obra estão sendo largamente utilizadas desde o início da década de $1990^{7}$, especialmente nos setores sucroalcooleiro e citrícola, como estratégia para reduzir custos de produção e ampliar a capacidade competitiva das empresas no mercado internacional, no contexto da abertura econômica e do fomento governamental à exportação agrícola. Almeida (2005) verificou que na safra 98/99 esta estratégia foi utilizada por $83 \%$ dos pequenos, $95 \%$ dos médios e $66,7 \%$ dos grandes produtores do setor citrícola do estado de São Paulo; na safra 99/00 os percentuais foram: $68,75 \%$, $86,6 \%$ e $75 \%$, respectivamente. Silva e Wensko (2003) analisaram 678 processos trabalhistas da Junta de Conciliação e Julgamento de Araraquara-SP, relativos ao período 1999 a 2001, constatando que 23 deles foram movidos contra este tipo de cooperativa.

Os assentamentos rurais paulistas têm sido ocupados por bóias-frias desempregados, trabalhadores com experiência de participação em cooperativas de mão-de-obra que atuam no corte da cana e/ou na colheita da laranja. Esta experiência, somada àquela vivida no processo de ocupação de terras orientado pelas diretrizes do MST, muito contribui para delinear o sentido contraditório que assume a cooperação nesses assentamentos (Scopinho et al., 2005).

\section{Cooperação e cooperativas no ideário e nas práticas do MST}

Entre os inúmeros aspectos da política de cooperação do MST, destaco aqui o seu significado econômico, social e político, os tipos de mecanismos instituídos para concretizar os princípios e como, historicamente, ela foi sendo construída no bojo da luta social empreendida em favor da reforma agrária.

A cooperação, entendida como ação social espontânea ou organizada, sempre foi essencial para o MST, desde a sua origem. É entendida como um processo de aprendizagem de longo tempo, que se inicia nos acampamentos antes mesmo da posse da terra, precisa ser continuamente revisado e assume diferentes formas, conforme se transformam as condições objetivas da realidade. Os dirigentes enfatizam que a cooperação não se resume na organização de cooperativas e que a luta pela terra é, por excelência, a experiência de cooperação mais importante para um Sem Terra.

Para nós a cooperação é mais do que cooperativas... Acho que o primeiro passo para cooperação no MST é quando as famílias começam a se organizar para ocupar a terra [grifos nossos]. Isto já é uma forma de se cooperar, de se ajudar para enfrentar um desafio, enfrentar uma dificuldade que é a conquista da terra (dirigente do MST/SP, 2002). ${ }^{8}$

Em princípio, para a maioria, a ocupação de terras pode não ocorrer por idealismo ou engajamento político, mas por motivos muito concretos relacionados à sobrevivência imediata. A necessidade de produzir alimentos para garantir a alimentação diária das famílias, de atender as necessidades essenciais de moradia, saúde e educação e de articular politicamente os acampados para enfrentar as pressões sociais e judiciais de estarem na condição de "invasores", apontam para o embrião do que significa a cooperação no MST que, por força das circunstâncias, são ensaiadas e desenvolvidas no acampamento.

No aspecto econômico, cooperar é um modo de organizar e administrar a produção que, através da divisão social do trabalho e da autogestão, soma esforços para adquirir e utilizar ferramentas, máquinas, sementes e matrizes de animais para produzir, individual e/ou coletivamente. A sobrevivência econômica dos assentados depende do aumento da produtividade do trabalho, do uso racional dos escassos recursos financeiros, naturais e humanos e da ampliação da competitividade dos produtos no mercado. 
... Estamos muito longe de ter a reforma agrária no Brasil. Nós temos políticas de experiências de assentamentos localizadas e com muitas dificuldades, nós temos uma distribuição de latifúndio de maneira massiva. Nós não temos uma política agrícola que garanta o crédito para os assentamentos, seguro agrícola, política de preços. São dificuldades que os assentamentos, que estas experiências de assentamentos enfrentam e a cooperação é fundamental para poder superar. Nas experiências de assentamentos que nós vivemos no Brasil a cooperação foi fundamental em todos aspectos e em todos os estágios (dirigente do MST/SP, 2002).

Economicamente, a cooperação configura-se como uma estratégia de proteção dos trabalhadores contra as adversidades historicamente vivenciadas pela pequena produção rural. É uma forma de administrar a escassez e enfrentar a pobreza, pois a quantidade de terra e os créditos recebidos do Estado para produzir são, individualmente, insuficientes. Neste aspecto, o cooperativismo desenvolvido pelo MST não se diferencia do cooperativismo tradicionalmente desenvolvido no Brasil. Se há uma diferença, ela está na tentativa de rever o modo de organização da produção, incorporando os princípios da agroecologia e da cooperação.

Porém, para o MST, a cooperação não contribuir apenas para melhorar as condições de vida do pequeno produtor no sentido da sobrevivência econômica e da geração de renda. Ao extrapolar o modo de organizar o processo produtivo, do ponto de vista social, ela pode ser também um recurso essencial para ampliar a possibilidade de acesso aos bens de consumo coletivo, tais como moradia, infraestrutura básica (água, energia elétrica, telefonia, estradas, transporte), educação, saúde, segurança, lazer etc. As famílias, geralmente, são assentadas onde não existe uma infraestrutura mínima adequada para constituir uma comunidade (Leite et al, 2004; Sparovek, 2003). ${ }^{9}$ É através da pressão e do esforço coletivo junto aos órgãos oficiais que este passivo social diminui e a terra, geralmente inóspita, aos poucos, transforma-se em pequenos vilarejos, comunidades organizadas. Esta dimensão da cooperação, favorecedora de condições para desenvolver a sociabilidade nos assentamentos, aliada à geração de renda, é essencial para possibilitar a permanência das famílias nos assentamentos e evitar novos êxodos rurais.

A dimensão política da cooperação diz respeito à própria continuidade do MST como entidade coletiva, mediadora da relação entre o indivíduo trabalhador rural Sem Terra e a sociedade, especialmente os proprietários de terra e o Estado. A cooperação organizativa e a solidariedade militante garantem a logística que sustenta a luta social pela conquista e permanência na terra. Esta dimensão revela-se mais claramente na mobilização, organização e realização das marchas, das ocupações, das diferen- tes formas de manifestação popular de massa, mas também acontece no cotidiano dos acampamentos e assentamentos através da repartição do que se arrecada ou se produz de alimentos, da troca de favores entre as famílias no cuidado com as crianças, jovens, idosos e doentes, nas pequenas ações de ajuda mútua sem as quais não haveria condições de sustentar e ampliar a capacidade de resistência.

Como dizem as lideranças, cooperar é, então, mais do que organizar cooperativas. É, sobretudo, ação organizada com base em valores mutualistas que se transforma em um importante recurso para superar as dificuldades decorrentes da insuficiência de políticas públicas, especialmente agrária e agrícola, que possibilitem ao trabalhador rural produzir e reproduzir-se no campo. Deste modo, a cooperação apresenta-se no ideário do MST como um meio de sobrevivência e resistência e não um fim em si mesma. As passagens grifadas no trecho de entrevista abaixo transcrito ilustram essas múltiplas dimensões e chamam a atenção para um outro elemento essencial: a existência de uma heterogeneidade articulada de formatos organizativos que se configuram dependendo da cultura, da capacidade de entendimento e das afinidades existente entre as pessoas e os grupos.

E é esta a nossa concepção: a de que a cooperação são diversas ações, é um conjunto de ações que podem ser mais complexas, menos complexas. Pode ser só na produção, pode ser também na vida social, na formação [técnica e política], enfim, em todos os aspectos, e que isto vai depender da cultura, da capacidade de entendimento daquele grupo e até de afinidade. Dependendo da situação do grupo, você pode avançar um pouco mais na cooperação. Dependendo da situação do grupo você tem um processo de cooperação só naqueles pontos essenciais que as famílias têm condição de entender e se cooperar. Então, a cooperação [grifos nossos] no nosso entendimento é o ato de fazer esforço múltiplo para superar as dificuldades (Dirigente do MST/SP, 2002).

Nos acampamentos e assentamentos, a cooperação concretiza-se através de uma constelação de formas organizativas diferentes - de grupos informais, associações e condomínios até os diferentes tipos de cooperativas que se enquadram em legislação específica,$-{ }^{10}$ estruturadas segundo o modo de apropriação da terra, do capital e do trabalho, a gestão da produção, a regulamentação legal e a organização das moradias. A diversidade de formas e a variedade de combinações indicam uma flexibilidade de arranjos organizativos que podem explicar a capacidade de sobrevivência e de reprodução das experiências. De acordo com a Confederação das Cooperativas de Reforma Agrária do Brasil ([CONCRAB], 1997), no processo organizativo das famílias, devem ser levados em conta tanto os elementos objetivos - nível de acumulação de capital existente, tipo de produto que é possível produzir, condi- 
ções naturais existentes no assentamento, existência de mercado consumidor - como subjetivos - o grau de consciência política, a história das comunidades na luta pela terra, as formas de trabalho e de produção por elas desenvolvidas anteriormente.

Apesar de não se resumir na organização formal de cooperativas, o MST criou mecanismos para concretizar os princípios e para institucionalizar o ato de cooperar, até porque as linhas oficiais de crédito para financiar a produção nos assentamentos somente são acessadas através de entidades coletivas e regulamentadas. ${ }^{11}$ Pode-se dizer que a cooperação somente foi institucionalizada no âmbito do MST por imposição do Estado, como forma de controlar o repasse dos recursos financeiros legalmente destinados à reforma agrária, na medida em que a pressão social dos assentados conquistou as linhas oficiais de crédito para o financiamento da produção, mas que apenas são obtidos através de entidades jurídicas que os representem junto ao Estado. Assim, favorecidos pela Constituição Federal de 1988, que garante liberdade de organização, e convencidos da necessidade de formalizar um sistema cooperativista alternativo ao existente representado pela Organização das Cooperativas do Brasil ${ }^{12}$ (OCB) - os assentados criaram em 1992 a CONCRAB. ${ }^{13}$

Se a institucionalização da cooperação foi imposta, as estratégias definidas para fazê-lo variaram conforme a conjuntura econômica e política do país, em dois momentos distintos. O primeiro ocorreu entre 1990 e 1994, por um lado, sob o impacto da abertura da economia e do mercado e das mudanças na política agrícola promovidas pelo governo Collor. A entrada de produtos agropecuários, principalmente através das negociações no âmbito do Mercosul, e as restrições impostas na concessão de créditos e subsídios, aliados à política intensiva de exportação, agravaram a crise na pequena agricultura e fez crescer o número de demandantes de terra no país. Por outro lado, a derrota da esquerda nas eleições de 1989 criou condições para o governo reprimir os movimentos populares e consolidar as reformas neoliberais. Para o MST estava claro que a cooperação era a única forma de estruturar os assentamentos conquistados até então, que se concentravam na região Centro-Sul do país, principalmente nos estados do Sul onde a tradição cultural européia favorecia o associativismo.

Nesta época, a Cooperativa de Produção Agropecuária (CPA) era vista tanto como uma estratégia para lidar com os poucos recursos financeiros disponíveis para enfrentar a crise da pequena agricultura quanto como uma opção política de desenvolvimento no campo, espécie de reduto de resistência (não armada) onde os militantes, na época bem menor em número e importância no cenário dos movimentos sociais brasileiros, poderiam abrigar-se, caso a repressão governamental contra as ocupações aumen- tasse. Foram organizadas mais de 40 CPAs no país, muitas inteiramente coletivistas, verdadeiras ilhas socialistas não só quanto à organização do trabalho, mas também quanto a certos aspectos da vida doméstica como, por exemplo, o uso de refeitórios e creches (A. F. G. Martins, 2004).

Porém, por volta de 1993, muitas CPAs entraram em crise resultando no aumento da evasão dos assentados. A crise é atribuída, principalmente, à falta de trabalho e renda decorrentes, internamente, da ausência de planejamento e controle administrativo que considerasse também a lógica do mercado e, externamente, da ausência de incentivo econômico por parte do Estado, ou seja, de política agrícola que tornasse o crédito acessível para os pequenos. Um outro importante fator atribuído à crise das CPAs é que este formato de cooperativa, inteiramente coletivo, não foi capaz de absorver a maioria da base social do MST. Essa maioria, fortemente vinculada aos tradicionais costumes rurais, tinha uma concepção de coletivo que não extrapolava os limites da família e uma compreensão restrita dos processos sociais e do papel subordinado da economia agrícola no desenvolvimento do país. Os assentados não se adaptaram ao formato organizativo da CPA, pois entendiam que a possibilidade de independência e liberdade estava no usufruto individual do lote de terra de que foram beneficiários. Em suma, o projeto CPA é considerado pelos dirigentes como sendo válido e até inovador em relação às inúmeras outras formas de cooperativismo existentes no campo. O problema é que, de um lado, por força das suas características rigidamente coletivistas e, de outro, pelas características sócio-culturais do trabalhador rural brasileiro, ele restringiu-se a uma minoria de militantes do MST. ${ }^{14}$

O segundo momento, entre 1994 e 2002, governo de Fernando Henrique Cardoso, foi marcado por novas crises na agricultura e no mercado financeiro, notadamente entre 1994 e 1997, quando até os médios e os grandes proprietários ficaram endividados. Este foi também o momento em que, apesar da repressão do Estado, a reforma agrária foi se fazendo aos poucos, por força da ampliação da base de apoio do MST e da adesão da sociedade mais ampla, inclusive no plano internacional. O episódio conhecido como Massacre de Eldorado de Carajás ${ }^{15}$ chamou a atenção dos ativistas de direitos humanos no âmbito internacional e ameaçou a imagem democrática do governo. $\mathrm{O}$ Estado mudou as suas estratégias na tentativa de minar a ação política do MST. Além de empreender forte campanha de desmoralização das lideranças de cooperativas acusando-as de desvio de dinheiro público, criou mecanismos mais sutis de desmobilização do movimento de reforma agrária como, por exemplo: o Banco da Terra, o Programa Nacional de Fortalecimento da Agricultura Familiar (PRONAF), o cadastro dos demandantes de terra via agência do correio, a instituição da figura do "empreendedor social" 16 que, em nome de uma suposta oferta de 
assistência técnica e social, realizava o controle político dos assentados.

O MST, por sua vez, optou por expandir a sua política de cooperação centrada nas cooperativas, mas agora criando as Cooperativas de Prestação de Serviços (CPS) porque, naquele momento, estavam convencidos de que a opção da maioria dos assentados não era o projeto socialista de politização supostamente contido na CPA, mas sim a melhoria das condições de existência no interior de cada lote, entendido como "pedaço de chão", ou seja, lugar que contém uma perspectiva de emancipação, de libertação da opressão vivida por falta de terras. Neste momento, para o MST, avançar na cooperação significava, sobretudo, criar formas de garantir a permanência no lote sem interferir na organização do trabalho ou da vida das pessoas, prover os assentamentos com os serviços ${ }^{17}$ necessários para conter a onda de evasão motivada pela falta de perspectiva das famílias de se reproduzirem minimamente ao serem assentadas. Se a crise das CPAs ocorreu, em parte, por problemas advindos da falta de planejamento e de orientação na aplicação dos créditos obtidos, a proposta da CPS surgiu para tentar suprir esta lacuna. A crise econômica foi, em certa medida, aliviada pelo crédito subsidiado advindo do Programa de Crédito Especial Para a Reforma Agrária (PROCERA), ${ }^{18}$ utilizado em parte na manutenção do lote para sustentar a permanência das famílias no assentamento, em parte para criar as CPSs.

Ocorreu que, acompanhando a logística organizativa do MST, as CPSs também assumiram uma dimensão regional, ou seja, foram criadas para atender regiões como, por exemplo, Cantagalo no Paraná e Pontal do Paranapanema em São Paulo. Essas eram áreas de concentração de assentamentos, mas eles tinham grau de organização heterogêneo no que se refere à produção, ao acúmulo de discussão política ou mesmo de motivação dos assentados para obter um melhor aproveitamento dos recursos investidos. Resultou que muitas cooperativas regionais foram criadas "de cima para baixo", motivadas apenas pela possibilidade de acessar os recursos das linhas de crédito. Com a extinção do PROCERA e a criação do PRONAF, esses grandes empreendimentos regionais não se sustentaram e faliram.

Considera-se que as CPSs, apesar de não contribuírem para consolidar a política de cooperação, em certa medida foram importantes porque viabilizaram a sobrevivência dos assentados num momento em que a reforma agrária era sinônimo de mera distribuição de terras e a pequena agricultura não encontrava outras formas de apoio institucional (preço, seguro), além das linhas de crédito mencionadas. Do ponto de vista organizativo interno, considerase que foi um equívoco deixar que a cooperação se reduzisse a uma política de criação de cooperativas, supondo que a institucionalização poderia solucionar os problemas político-organizativos, porque isto somente ocorre quando as organizações estão sustentadas por um movimento social forte. Mesmo concebendo a cooperativa como uma ferramenta de luta política e social ocorre que, na prática, ela é culturalmente tida como meio de organizar exclusivamente a atividade econômica e, no dia-a-dia, esta sua dimensão prevalece e até se sobrepõe à dimensão políticoorganizativa. Ou seja, a experiência mostrou que a criação de cooperativas, em si, não organiza politicamente os assentamentos. Ao contrário, as exigências legais e administrativas advindas a institucionalização da cooperação podem acarretar uma carga burocrática intensa e consumir grande parte do tempo dos dirigentes que, depois de alguns anos, não conseguem visualizar mais do que os problemas do cotidiano. Assim, a cooperativa se distancia da participação política pois a "máquina" econômica e administrativa passa a dar o tom na organização e os dirigentes são por ela consumidos, mesmo estando técnica e politicamente preparados.

A. F. G. Martins (2004) pontuou as cinco contradições fundamentais responsáveis pelas tensões sofridas pela política institucional de cooperação do MST na década de noventa, as denominadas "heranças contraditórias do processo histórico" (p. 171), a saber: o legalismo, o comodismo, a cultura da dependência, a institucionalização da cooperação e o método utilizado no processo organizativo. Na opinião deste autor, a institucionalização da cooperação no MST, apesar dos esforços e da boa vontade dos militantes, apenas reforçou a concepção de mundo dominante, causou impactos negativos na organização da produção e o endividamento dos assentados, porque não diversificou a produção, não mudou a base tecnológica, teve como base organizativa a empresa econômica e como base financeira o crédito subsidiado e se utilizou dos canais convencionais de comercialização.

Em suma, para a CONCRAB, a cooperativa, enquanto entidade econômica, somente tem um papel político a cumprir se o grupo que a empreender tiver um ideal ou um projeto político claro. Por este motivo, o cooperativismo, como modelo organizativo, vem perdendo lugar na agenda organizativa do MST. Por outro lado, a cooperação, enquanto prática e processo social que contribui para organizar o trabalho e a vida cotidiana resgatando valores, tradições e práticas mutualistas, até por força das inúmeras necessidades enfrentadas no cotidiano, vêm ganhando força.

A idéia de cooperação ocupa um lugar tão importante quanto à de agroecologia como diretriz e método do processo organizativo. Considera-se que é necessário dar outro significado ao trabalho rural revendo o modo de organizar a produção, para não reproduzir o modelo agropecuário tradicional. No que se refere à base técnica, a orientação é colocar a tecnologia em favor do homem e não o con- 
trário, ou seja, utilizá-la para proteger e perpetuar os recursos naturais e, principalmente, diminuir os custos de produção através da utilização de insumos e métodos agroecológicos. Quanto ao modo de organizar a produção, a cooperação tem sido vista como uma saída para enfrentar e superar as dificuldades e a escassez de recursos decorrentes da ausência de políticas públicas que favoreçam a pequena produção e o desenvolvimento sócio-cultural e político dos assentados.

No entanto, percebe-se que não basta divulgar uma concepção de cooperação que extrapola o econômico, construir canais de articulação e formação política-ideológica e mecanismos de institucionalização. Permanece o desafio de superar os obstáculos concretos que se colocam entre a concepção e as práticas de cooperação.

São dois grandes tabus, dois grandes desafios que a gente tem que superar para a gente fazer o novo que é: uma agricultura alternativa, sem agrotóxico, agricultura orgânica é um desafio; e o outro é o jeito que a gente vai produzir, que é não mais pensar individualmente, mas começar a pensar conjuntamente com outros companheiros... [a cooperação] traz consigo não só a questão da organização da produção, mas também a organização da vida das pessoas. Que é um processo... Talvez, mais difícil do que trabalhar a produção é trabalhar a construção destas novas relações humanas de companheirismo, de afetividades, do novo... Porque se tu tiver problemas na convivência traz problemas na produção, traz problemas de auto-estima, de tu estar feliz no espaço que tu está. De tu produzir mais e melhor, ser criativo (dirigente do MST/SC, 2002).

Ocorre que, na prática, para o trabalhador rural assentado, a concepção de cooperação que extrapola o âmbito da sua própria família é tão complexa e polêmica quanto à de agroecologia, tal como ela é tecnicamente difundida pelos adeptos do movimento ambientalista. O conservadorismo das práticas agropecuárias depredatórias e dos valores individualistas e patriarcalistas estão entre os obstáculos considerados mais importantes e, ao mesmo tempo, difíceis de transpor, quando se trata de desenvolver a cooperação nos assentamentos rurais.

\section{Considerações Finais}

A avaliação continuada da política e das práticas de cooperação empreendida nos últimos anos tem levado a CONCRAB a investir mais na cooperação espontânea e menos na institucionalização das experiências. De fato, observa-se que nos acampamentos e assentamentos a cooperação acontece à revelia das leis e das políticas públicas. ${ }^{19}$ Se for no acampamento que tem início a difícil tarefa e a trajetória desses trabalhadores na direção da mudança no modo de conceber e praticar a cooperação, entendida no sentido econômico, social e político, convém verificar se a vivência como acampado e a participação no MST são suficientes para promover a mudança. Como se dá a construção deste novo homem, que estabelece novas relações de trabalho? Como é possível enfrentar o desafio de manter as tradições culturais do mundo rural sem reproduzir as relações sociais típicas?

A análise das contradições que emergem da relação que se estabelece entre as estruturas organizativas/organizacionais e a ação desses sujeitos, considerando a realidade política e econômica, pode ajudar a responder essas questões. A cooperação não depende apenas da criação de estruturas (cooperativas, associações etc), do treinamento de habilidades ou da educação dos sujeitos para o exercício da solidariedade. Nos assentamentos rurais, as relações de cooperação são mediadas por um conjunto de condicionantes estruturais que são (ou não) dados, especialmente, a partir da relação estabelecida com o Estado, cuja responsabilidade na reforma agrária não se resume na mediação dos conflitos fundiários e na redistribuição de terras e se estende, sobretudo, na viabilização dos assentamentos ao criar as condições de infra-estrutura sem as quais não se sustenta a organização, por mais autônoma e politicamente preparada para o exercício da cooperação que a comunidade esteja. É ainda mediada pelo próprio sentido atribuído pelos trabalhadores rurais à cooperação e à cooperativa.

A busca de compreensão para essas questões tem motivado a continuidade das minhas investigações neste campo. As respostas não são simples e nem definitivas porque mesmo diante da ausência de condições objetivas e da presença de medidas impositivas, os assentados inventam novas ações e novos formatos organizativos para a cooperação. Mesmo lhe atribuindo sentidos contraditórios, eles procuram equacionar a diversidade de interesses e de experiências existente e, ao mesmo tempo, atender as exigências para legalizar os assentamentos tornandoos espaços sociais de enraizamento e pertença, até por falta de alternativas. Por isto, a reflexão aqui proposta não é conclusiva. Apenas acena para o desafio de repensar os esquemas analíticos simplificadores e reducionistas que, ao procurar compreender a cooperação e o processo organizativo nos assentamentos rurais, enfocam ou apenas os aspectos técnicos e econômicos responsáveis pela eficácia/ eficiência ou apenas os aspectos político-sociais, ligados ao exercício da democracia.

\section{Notas}

\footnotetext{
Vários autores referiram-se às formas de organização do trabalho rural fundamentadas na cooperação espontânea. Para J. S. Martins (1996), a expansão do capitalismo na agricultura redefiniu as antigas relações de produção ao mesmo tempo em que integrou as relações não capitalistas, estas caracterizadas por serem não
} 
assalariadas. Isto porque o pequeno produtor rural que dispunha de pouco capital lançava mão de estratégias de sobrevivência como a demão, o mutirão, a troca de dias e o rodízio de mão-deobra, principalmente no plantio e na colheita, para garantir a reprodução social da família e a permanência na terra. Queiroz (1973) e Fukui (1979), analisando a dinâmica dos bairros rurais paulistas, mostraram que, diante da escassez, o trabalho coletivo - "trabalho rural em comum" (Queiroz, 1973, p. 4) e o "ajutório" (Fukui, 1979, p. 166) - era, depois da religião, a segunda forma mais importante de sociabilidade. Esta mesma literatura mostra que, contraditoriamente, quanto mais as relações de produção capitalistas desenvolveram-se no campo, mais as formas de trabalho baseadas na cooperação espontânea foram abandonadas.

2 O movimento cooperativista brasileiro surgiu no início do século XX por livre iniciativa de pequenos produtores inspirada nos emigrantes europeus, que se reuniam em cooperativas do tipo agrícola ou de consumo para aumentar a taxa de lucro através da eliminação de intermediários. Rios (1976) mostrou que o cooperativismo nasceu da iniciativa popular para solucionar o problema da carestia e da insuficiência de abastecimento de gêneros alimentícios básicos nos centros urbano-industriais emergentes, mas tornou-se política estatal na década de 1930, tanto pelo seu potencial econômico quanto ideológico de caráter reformista, uma vez que contribuía para resolver problemas de abastecimento interno e modernizava a produção agrícola inserindo-a no mercado, ao mesmo tempo em que justificava a intervenção estatal na economia, em nome dos menos favorecidos.

3 O autor refere-se à Cooperativa dos Pioneiros Eqüitativos de Rochdale, criada na Inglaterra em 1844, experiência amplamente referida na literatura especializada por ter inspirado os princípios cooperativistas difundidos mundialmente desde então.

4 Esta legislação permanece praticamente intocada até hoje, apesar das críticas que sempre recebeu e do recente movimento em favor da revisão, dada a sua inadequação ao atual contexto cooperativista brasileiro. Na época da sua aprovação, contribuiu para dinamizar o movimento cooperativista conferindo-lhe uma orientação nitidamente empresarial, pois estimulou a fusão de cooperativas agrícolas isoladas e criou condições para integração vertical de cooperativas consolidadas, além de isentá-las de impostos. As primeiras cooperativas foram criadas em 1906 e as que vingaram, em 1920. O primeiro decreto regulamentar data de 19/12/1932 - decreto 22.239-, assumia os princípios de Rochdale e conferia às cooperativas alguns incentivos tributários especiais, pois o governo Vargas decidiu investir no movimento como instrumento de desenvolvimento econômico-social. Em 1933 foi criado o Departamento de Assistência ao Cooperativismo (DAC) em São Paulo. Nesta época, o movimento sindical, nascido por obra do Estado, também promovia o cooperativismo, especialmente de consumo, transformando-o em bandeira de salvação contra o custo de vida. Entre 1966 e 1971, promovendo a livre concorrência, o governo militar cancelou alguns benefícios tributários, restringiu crédito e proibiu operações com terceiros, situação que foi revertida com a lei 5.764, de 1971, que restabeleceu os benefícios e eliminou as proibições, dinamizando o setor. Entre 1932 e 1971 a legislação sofreu poucas modificações através do decreto-lei 581 de 01/08/1938 e do decreto 8401, de 19/12/1945. Para um detalhamento da história da institucionalização do cooperativismo no Brasil ver Araújo (1982), Camargo (1960) e Fleury (1983).

5 Este autor distinguiu doutrina cooperativa - falsa teoria que se impõe à prática, não reflete e nem se adapta à realidade - de teoria cooperativa - deriva de vivência e observação sistemática da prática, que a enriquece e transforma (Rios, 1989, p. 51).
6 São genericamente chamados de "gatos" os que subcontratam e/ ou intermediam a contratação da força de trabalho temporária (os “safristas") utilizada nas agroindústrias. Esses personagens são assim denominados porque aparecem como exploradores, verdadeiros "vilões" da história das relações trabalhistas, segundo os trabalhadores rurais. No imaginário popular rural o gato é tido, geralmente, como um animal esperto, sorrateiro, egoísta e traiçoeiro, que é capaz de roubar o próprio dono.

7 A criação dessas cooperativas é respaldada pelo artigo 90 da lei 5.764/1971, que dispõe sobre a não existência de vínculo empregatício entre a cooperativa e seus associados, e da lei 8.949/1994, que mudou a redação do artigo 442 da Consolidação das Leis do Trabalho (CLT) acrescentando não haver vínculo empregatício entre associados, cooperativas e seus tomadores de serviços em qualquer ramo de atividade econômica. Estes dispositivos legais abriram precedentes para as grandes agroindústrias utilizarem a força de trabalho sem garantir vínculo empregatício ou qualquer outro direito trabalhista, o que precarizou ainda mais o trabalho dos assalariados rurais (Almeida, 2005; Scopinho, 2003). Ao mesmo tempo, esses mesmos dispositivos legais favoreceram a criação de cooperativas de produção agropecuária pelos assentados da reforma agrária porque as desobriga do pagamento de encargos trabalhistas aos associados.

8 Os trechos de entrevista utilizados neste tópico foram extraídos de Scopinho e Martins (2002).

9 Sparovek (2003) constatou que nos assentamentos rurais formados entre 1993 e 2001, 32\% dos assentados não possuíam moradia definitiva e ainda habitavam os precários barracos de lona preta, $49 \%$ não tinham água potável, $55 \%$ não tinham rede elétrica, $62 \%$ não ofereciam atendimento de emergência à saúde, $77 \%$ dos assentados não tinham acesso ao ensino médio e $29 \%$ das famílias que possuíam filhos em idade escolar não tinham acesso ao ensino fundamental.

10 Essas diferentes formas aglutinam-se no que se denomina Sistema Cooperativista dos Assentados (SCA), cuja finalidade é a de mobilizar e organizar politicamente os assentados através da formação de núcleos de famílias, entendidos como instâncias básicas na gestão do assentamento (CONCRAB, 1999).

11 A política organizativa da cooperação nos assentamentos iniciouse tão logo o MST estruturou-se em 1986, como um movimento que reivindica terra para os trabalhadores rurais, a partir da organização dos coletivos de produção informais. No mesmo ano ocorreu em Cascavel (PR) o IEncontro Nacional dos Assentados que, defendendo a tese da continuidade acampamento-assentamento no que se refere à luta pela reforma agrária (entendida não só como distribuição de terra, mas também como garantia de condições para torná-la produtiva), definiu como prioridade a busca de recursos para a produção nos assentamentos e promover a cooperação a partir da constituição de pequenos grupos de famílias para facilitar o controle e a gestão. Ainda na década de oitenta, uma importante conquista da organização dos assentados foi a obtenção de uma linha oficial de crédito subsidiado para os assentados denominada PROCERA (A. F. G. Martins, 2004).

12 Para a CONCRAB, o cooperativismo praticado pela OCB é tradicional porque, apesar de orientado pelos Princípios de Rochdale, reproduz a lógica capitalista ao agregar grandes e pequenas empresas, sustentar as relações de subordinação que se estabelecem entre elas no âmbito da produção e do mercado e contratar força de trabalho assalariada para promover o agronegócio de exportação (CONCRAB, 1997).

13 Segundo os dirigentes, a fundação da CONCRAB foi respaldada por um longo processo de estudo, debates e visitas realizadas em 
outros países para conhecer diferentes tipos de experiências, especialmente as de Cuba, China, Israel e Espanha. Trata-se de uma figura jurídica, estruturada nos moldes da legislação cooperativista brasileira vigente, ou seja, possui uma instância federal e cooperativas estaduais às quais se filiam unidades locais. Atualmente, há nove cooperativas estaduais filiadas (localizadas nos estados de RS, SC, PR, SP, BA, ES, PE, CE, MA) e nos demais estados existem os coletivos estaduais do SCA. A sua principal função é desenvolver programas específicos tais como: experimentação de novas propostas de assentamentos, acompanhamento econômico e organizativo das cooperativas de produção, crédito ou comercialização, capacitação técnica das lideranças e de jovens agricultores e estudos de mercado.

14 Para uma análise detalhada sobre o funcionamento e o significado das CPAs organizadas pelo MST, além dos documentos da CONCRAB citados, pode-se consultar Christoffoli (2000), Pagotto (2003) e A. F. G. Martins (2004), entre outros.

15 Conflito fundiário ocorrido em 1996, em Eldorado de Carajás (PA), que se tornou um marco na história recente da violência e das lutas sociais no campo, pelo número de mortes causadas devido ao confronto da polícia com os acampados.

16 Órgãos estatais como a Empresa Brasileira de Pesquisa Agropecuária (EMBRAPA) e a Fundação Instituto de Terras do Estado de São Paulo (ITESP) realizaram concursos públicos para contratar um verdadeiro exército de técnicos qualificados em diversas áreas do conhecimento para "organizar" os assentamentos.

17 Por serviço entendia-se tudo aquilo que pudesse dar suporte ao trabalho familiar realizado nos lotes: utilização de máquinas, compra de insumos, beneficiamento da produção, criação de canais de comercialização, oferta de transporte e condições adequadas de armazenamento, elaboração de projetos, oferta de assistência técnica especializada, entre outros recursos fundamentais para viabilizar a produção, que não eram oferecidos através das políticas públicas e se eram, custavam o preço da obediência às normas e a submissão ao controle do Estado.

18 O chamado Teto II do PROCERA era uma linha específica de crédito coletivo oficial para integralização de cotas-parte em cooperativas formalizadas, liberado em abundância nos primeiros anos do governo Fernando Henrique Cardoso.

19 No cotidiano, a cooperação se desenvolve, especialmente, através das mulheres que produzem no entorno da moradia e criam, por forças das suas circunstâncias de vida, modos de troca e de apoio mútuo que garantem a manutenção das famílias. A ação das mulheres, informal, pequena e silenciosa, ganha importância na política de cooperação do MST e as relações de gênero devem ser problematizadas, quando o objetivo é entender os seus novos matizes (Scopinho et al., 2005).

\section{Referências}

Almeida, L. M. M. (2005). “Novas” formas de contratação de mãode-obra rural no complexo agroindustrial citrícola paulista. Dissertação de Mestrado não-publicada, Programa e Pós-Graduação em Engenharia de Produção, Universidade Federal de São Carlos, São Carlos, SP.

Araújo, S. M. P. (1982). Eles: A cooperativa - Um estudo sobre a ideologia da participação. Curitiba, PR: SECE.

Bruni, L. (2005). Comunhão e as novas palavras em economia. São Paulo, SP: Cidade Nova.

Camargo, L. C. (1960). Cooperação e cooperativismo: Vol. 4. Cadeira 20. São Paulo, SP: Editora da Universidade de São Paulo.
Cavendish, S. (1981). Cooperativismo e dominação. In M. R. Loureiro (Ed.), Cooperativas agrícolas e capitalismo no Brasil (pp. 75-95). São Paulo, SP: Cortez.

Christoffoli, P. (2000). O desenvolvimento de cooperativas de produção coletiva de trabalhadores rurais no capitalismo: Limites e possibilidades. Dissertação de Mestrado não-publicada, Programa de Pós-Graduação em Administração, Universidade Federal do Paraná, Curitiba, PR.

Confederação das Cooperativas de Reforma Agrária do Brasil. (1997). Cooperativas de Produção-Questões práticas: Vol. 21. Cadernos de Cooperação Agrícola (3. ed.). São Paulo, SP: MST.

Confederação das Cooperativas de Reforma Agrária do Brasil. (1999). A evolução da concepção de cooperação agrícola do MST: Vol. 8. Cadernos de Cooperação Agrícola. São Paulo, SP: MST.

Fleury, M. T. L. (1983). Cooperativas agrícolas e capitalismo no Brasil. São Paulo, SP: Global.

Fukui, L. F. G. (1979). Sertão e bairro rural. São Paulo, SP: Ática.

Leite, S., Heredia, B., Medeiros, L., Palmeira, M., \& Cintrao, R. (Eds.). (2004). Impacto dos assentamentos. Um estudo sobre o meio rural brasileiro. São Paulo, SP: Editora da Universidade Estadual Paulista.

Loureiro, M. R. (1981). Cooperativismo e reprodução camponesa. In M. R. Loureiro (Ed.), Cooperativas agrícolas e capitalismo no Brasil (pp. 133-155). São Paulo, SP: Cortez.

Maia, I. (1985). Cooperativa e prática democrática. São Paulo, SP: Cortez.

Martins, A. F.G. (2004). Potencialidades transformadoras dos movimentos camponeses no Brasil contemporâneo: As comunidades de resistência e superação do MST. Dissertação de Mestrado não-publicada, Programa e Pós-Graduação em Ciências Sociais, Pontifícia Universidade Católica de São Paulo, SP.

Martins, J. S. (1996). O Cativeiro da Terra (6. ed.). São Paulo, SP: LECH.

Ministério do Desenvolvimento Agrário. (2000). Projeto de Desenvolvimento Sustentável-PDS. Brasília, DF: Autor.

Novaes, J. R. (1981). Cooperativismo: Acumulação e mudança social. In M. R. Loureiro (Ed.), Cooperativas agrícolas e capitalismo no Brasil. (pp. 41-73). São Paulo, SP: Cortez.

Pagotto, C. (2003). Ajustes e rupturas: Cooperativismo e lutas sociais no Brasil contemporâneo. Dissertação de Mestrado nãopublicada, Programa de Pós-Graduação em Ciências Sociais, Pontifícia Universidade Católica de São Paulo, SP.

Pinho, D. B. (2004). O Cooperativismo no Brasil: Da vertente pioneira à vertente solidária. São Paulo, SP: Saraiva.

Queiroz, M. I. P. (1973). Bairros rurais paulistas: Dinâmica das relações bairro rural-cidade. São Paulo, SP: Duas Cidades.

Rios, G. S. L. (1976). Cooperativas agrícolas no nordeste brasileiro e mudança social. Dissertação de Mestrado não-publicada, Programa e Pós-Graduação em Economia Rural, Universidade de São Paulo, Piracicaba, SP.

Rios, G. S. L. (1989). O que é cooperativismo (2. ed.). São Paulo, SP: Brasiliense.

Schneider, J. E. (1981). O cooperativismo agrícola na dinâmica social do desenvolvimento periférico dependente: O caso brasileiro. In M. R. Loureiro (Ed.), Cooperativas agrícolas e capitalismo no Brasil (pp. 11-40). São Paulo, SP: Cortez.

Scopinho, R. A. (2003). Vigiando a vigilância: saúde e segurança no trabalho em tempos de qualidade total. São Paulo, SP: Editora da Fundação de Amparo à Pesquisa do Estado de São Paulo.

Scopinho, R. A., \& Martins, A. F.G. (2002). Imagens da terra: Trabalho e vida nos assentamentos de reforma agrária do Movi- 
mento dos Trabalhadores Rurais Sem Terra-MST [CD-ROM]. São Paulo, SP: Macromídia.

Scopinho, R. A., Martins, A. F. G., Marçal, C. R. M., Russo, P. I. F., Pereira, D. E. M., Oliveira, C. A., Rezende, J. R., \& Santos, J. A. (2005). A cultura em organizações econômicas populares autogestionárias: Cooperação e contradições do processo organizativo. São Carlos, SP: Universidade Federal de São Carlos. (Relatório de Pesquisa, CNPq/Edital 06/03, processo 40.2968/2003-4).

Silva, M. A. M., \& Wensko, A. A. (2003, out.). Trabalhadores rurais em luta pelos direitos. In Anais do XXVI Encontro Anual da Associação Nacional de Pós-Graduação e Pesquisa em Ciências Sociais: Trabalho, Sindicatos e a Nova Questão Social (pp. 286306). Caxambu, MG: ANPOCS.

Singer, P. (2002). Introdução à economia solidária. São Paulo, SP: Perseu Abramo.

Sparovek, G. (2003). A qualidade dos assentamentos de reforma agrária brasileira. São Paulo, SP: Páginas \& Letras.

Rosemeire Aparecida Scopinho é graduada em Psicologia pela Universidade de São Paulo (USP),

Mestre em Fundamentos da Educação pela Universidade Federal de São Carlos (UFSCar) e Doutora em Sociologia pela Universidade Estadual Paulista - Araraquara-SP. É professora adjunta no Departamento de Psicologia da UFSCar, onde atua nas áreas de Psicologia Social e Psicologia do Trabalho. Coordena o Grupo de Pesquisa Trabalho, Organização Social e Comunitária, que se ocupa do estudo dos impactos psicossociais e culturais das transformações que atualmente se processam no mundo do trabalho no âmbito de organizações autogeridas e heterogeridas. É pesquisadora do Grupo de Pesquisa Trabalho e Processos Organizativos na Contemporaneidade. É co-autora dos livros Saúde e Trabalho no Sistema Único de Saúde (Editora HUCITEC, 1994), Modernização e Impactos Sociais: o caso da agroindústria canavieira da região de Ribeirão Preto-SP (Editora FASE, 1995) e Velhos Trabalhos Novos Dias: modos atuais inserção de antigas atividades laborais (Editora EDUFSCar; Editora da UFC, 2006). É autora do livro Vigiando a Vigilância: Política e prática de saúde e segurança no trabalho em tempos de qualidade total (Editora Annablume; FAPESP, 2003) e de artigos publicados em revistas especializadas. Endereço para correspondência: Departamento de Psicologia - UFSCar. Telefone: (16) 3351-8361,

(16) 3351-8489 (fax). scopinho@power.ufscar.br

\section{Sobre cooperação e cooperativas em assentamentos rurais}

Rosemeire Aparecida Scopinho

Recebido: 06/07/2006

$1^{\mathrm{a}}$ revisão: $10 / 11 / 2006$

Aceite final: 28/11/2006 